\title{
Influence of ambient gases on the dc saturated breakdown field of molybdenum, tungsten, and copper during intense breakdown conditioning
}

\author{
T. Ramsvik, S. Calatroni, A. Reginelli, and M. Taborelli \\ European Organization for Nuclear Research, CERN, 1211 Geneva 23, Switzerland
}

(Received 13 October 2006; published 12 April 2007)

\begin{abstract}
A comprehensive investigation of the effect of $\mathrm{Ar}, \mathrm{H}_{2}$, air, and $\mathrm{CO}$ on the saturated breakdown field $\left(E_{\mathrm{sat}}\right)$ of molybdenum, tungsten, and copper has been performed at intensive breakdown conditioning. A significant decrease in $E_{\text {sat }}$ is observed for molybdenum and tungsten when exposed to air. Specifically, at air pressures of $\sim 10^{-5}$ mbar, the decrease in $E_{\text {sat }}$ is found to be up to $50 \%$ and $\sim 30 \%$ compared to UHV conditions for molybdenum and tungsten, respectively. In addition, a $\sim 30 \%$ decrease is found when molybdenum is conditioned with a $\sim 10^{-5}$ mbar CO pressure. Surface analysis measurements and breakdown conditioning in $\mathrm{O}_{2}$ ambience imply that the origin of the decrease in $E_{\text {sat }}$ is closely linked to oxide formation on the electrode surfaces. Ex situ heat treatment of molybdenum is shown to improve the breakdown characteristics drastically.
\end{abstract}

DOI: 10.1103/PhysRevSTAB.10.042001

PACS numbers: 52.80.Vp, 52.80.Pi, 29.30.Dn, 29.17.+w

\section{INTRODUCTION}

Long-term reliability of high voltage devices using vacuum as the insulating medium is important for many industrial and scientific applications. The maximum breakdown field and the processes leading to breakdown depend strongly on parameters like electrode material, gap size, initial roughness and geometry, vacuum quality, erosion, etc. [1]. The breakdown measurements reported in this paper use gap sizes in micrometer range, making these measurements particularly relevant for applications such as vacuum microelectronics (see e.g. [2,3]) and rf linear accelerators [4], where field emission initiated processes are believed to be the dominating source of electrical breakdown events.

At CERN the feasibility of a $30 \mathrm{GHz}$ multi-TeV $e^{+} e^{-}$ Compact LInear Collider (CLIC) is under investigation [5]. To reach the required energy level within feasible length of the linacs, the highest possible accelerating gradient is chosen, yielding surface fields of $\geq 300 \mathrm{MV} / \mathrm{m}$ within the accelerating structure. To guarantee sufficiently low breakdown rates during operation, novel solutions of the choice of iris materials are needed [6]. The obvious complexity in testing various iris materials at the nominal CLIC values of the radio frequency triggered a comprehensive study of dc breakdown fields of refractory metals in ultrahigh vacuum (UHV) and micrometer sized gaps. Recent results indicate that a direct comparison of achieved saturated breakdown fields $\left(E_{\text {sat }}\right)$ from tests with $30 \mathrm{GHz}$ rf and dc voltages are indeed meaningful [7].

During the first runs of the new CLIC Test Facility, CTF3 [8], substantial pressure bursts were detected inside the accelerating structure at the moment of breakdown, causing degradation of the initial vacuum condition [9]. In this paper, the long-term effects of such degradation are investigated for copper $(\mathrm{Cu})$, tungsten $(\mathrm{W})$, and molybdenum (Mo), i.e., materials presently considered as possible candidates for iris materials in the accelerating structure. In an experiment aimed to test the high-gradient acceleration, molybdenum proved to be most promising [6]. Hence, gas results from molybdenum are in this paper emphasized.

The influence of gas on the breakdown field has been investigated for decades [1,10]. Jüttner et al. [11] studied the long-term effect of the corrosive action $\mathrm{CO}, \mathrm{CO}_{2}$, and $\mathrm{H}_{2} \mathrm{O}$ have in the pressure range $10^{-10}-10^{-7}$ mbar, using copper, molybdenum, and tungsten as electrode materials. The experimental findings showed that the originally atomically clean surface becomes progressively "granulated" by the formation of numerous secondary submicroscopic electron emission centers with emitting area dimensions of $\sim 5-10 \mathrm{~nm}$. Jüttner et al. also studied the variation of the released ion current from a contaminated cathode as a function of the number of breakdown events $[10,12]$. The results indicated that the breakdown arc initially erodes into the oxide layers, followed by further erosion into the underlying bulk metal.

The aim of this paper is to perform a detailed investigation of how various gases influence the saturated breakdown field $\left(E_{\text {sat }}\right)$ of some selected electrode materials during extensive breakdown conditioning.

\section{EXPERIMENTAL}

The breakdown experiments reported in this paper are performed using an experimental setup described in detail by Kildemo [13]. The UHV chamber houses two electrodes of tip-plane geometry, where their relative distance can be regulated at submicrometer precision using a custom-made mechanical micropositioning tool. The tip anode can be subjected to voltages ranging from 0 to $15 \mathrm{kV}$ by discharging a $27 \mathrm{nF}$ capacitor through a series of high voltage relays. Applied electrical fields up to $1 \mathrm{GV} / \mathrm{m}$ in the gap junction between the electrodes are thus reached. A true electrical breakdown over the gap is acknowledged 
(A)

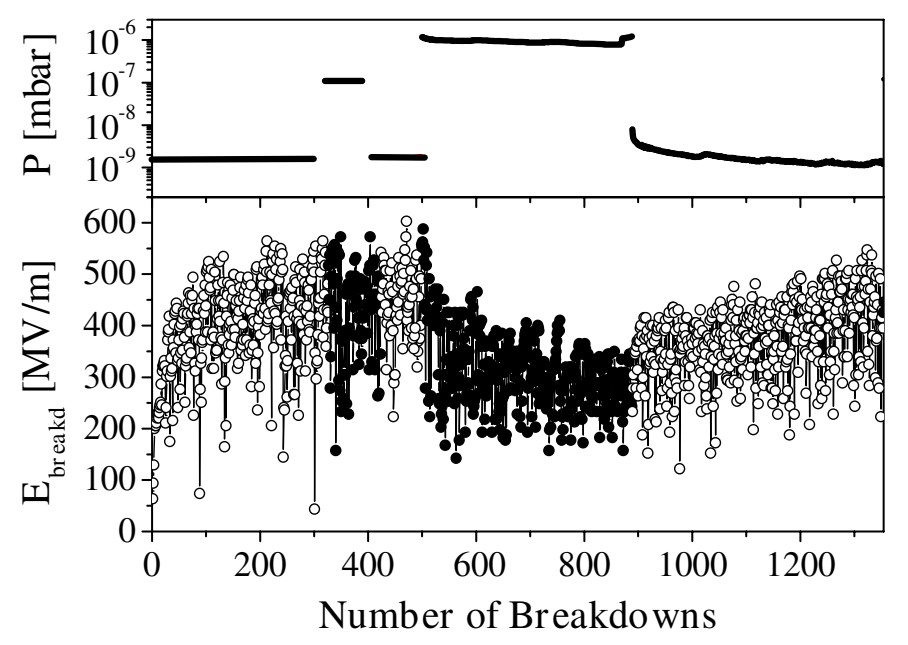

(B)

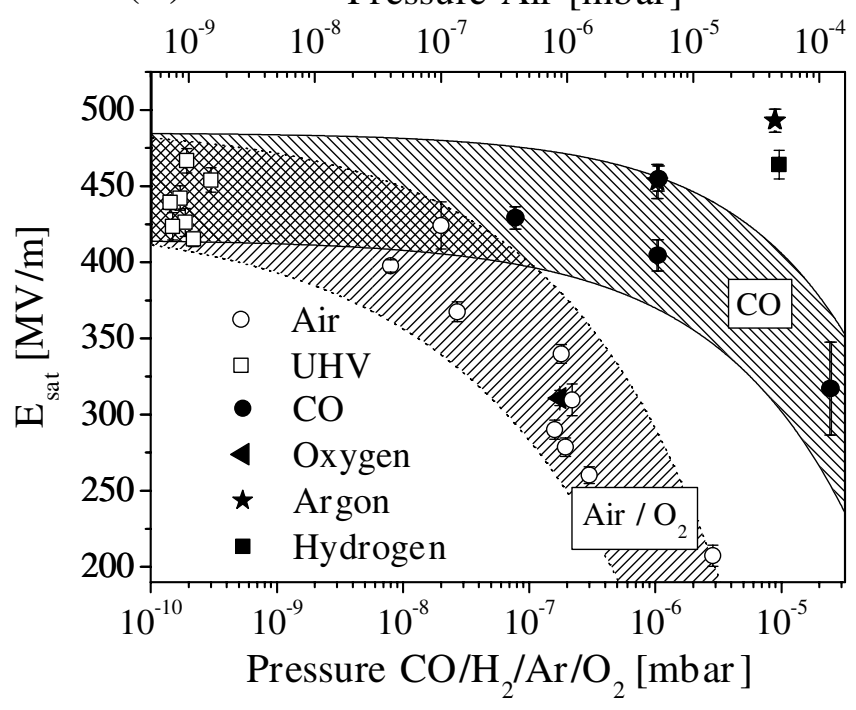

FIG. 1. Breakdown fields for molybdenum in UHV and the effect of gas pressures of air, $\mathrm{O}_{2}, \mathrm{CO}, \mathrm{H}_{2}$, and argon. (A) The lower graph shows the conditioning curve of molybdenum, where the vertical axis gives the maximum achieved applied electric field in $\mathrm{MV} / \mathrm{m}$ before breakdown. The upper graph shows the average pressure of air for each measurement point. The horizontal axis gives the accumulated number of breakdowns with constant cathode/anode position. (B) Variation of the saturated breakdown field (vertical axis) with gas pressures (horizontal axes). The upper horizontal axis shows the absolute pressure of air, and is shifted by a factor of 5 to higher values relative to the lower axis. The shaded areas surrounding the data points symbolize the variation as a function of air and CO pressure, respectively. The vertical bars denote the resulting standard deviations.

when a full discharge of the capacitor takes place, and a high current pulse is measured over the gap junction. Automated data acquisition and control are accomplished with LabView data acquisition software using an IEEE488 interface bus. In the following, the breakdown field is defined as the maximum applied field that can be applied to the electrodes before breakdown. Since this value changes by repeating breakdown events along a conditioning curve on the same sample site, a saturation field, $E_{\text {sat }}$, is here defined as the breakdown field obtained by a Gaussian fit over a histogram of many single breakdown field events [7].

The accuracy of the gap distance is checked before and after a complete conditioning by reestablishing contact between the two electrodes.

For all the experiments reported in this paper, identical materials were chosen for the anode and the cathode. The cathodes and anodes consist of polycrystalline sheets of $0.5-1 \mathrm{~mm}$ thickness, and $2.3 \mathrm{~mm}$ thick rods with hemispherical apex, respectively. The samples are $99.9 \%$ purity molybdenum, $99.95 \%$ purity tungsten, and OFE-copper. Prior to be installed in the UHV chamber, all materials were cleaned according to the CERN standard procedure for UHV components [14]. When bakeouts were performed to reach UHV, the vacuum chamber was heated to typically $150{ }^{\circ} \mathrm{C}$ for 24 to $48 \mathrm{~h}$. During breakdown conditioning experiments, commercial gases with the following purity were used: Ar: 99.9999\%; $\mathrm{N}_{2} / \mathrm{O}_{2}$ : 99.9999\%/99.9995\% (dry air); $\mathrm{O}_{2}: 99.99 ; \mathrm{H}_{2}: 99.997 \%$.
All x-ray photoemission spectroscopy (XPS) measurements described have been carried out with a PHI ESCA 5400 multipurpose system equipped with a spherical sector electron spectrometer (PHI model 10-360) operated at fixed pass energy and a nonmonochromatized $\operatorname{MgK} \alpha$ $\mathrm{x}$-ray source. The analyzed sample area can be selected between about $1 \times 1 \mathrm{~mm}^{2}$ and $3 \times 3 \mathrm{~mm}^{2}$ by a movable slit and the electrons are collected at a takeoff angle of $45^{\circ}$ from the surface. Energy scale calibration is made with $\mathrm{Cu}$ $2 p^{3 / 2}$ and $\mathrm{Au} 4 f^{7 / 2}$ lines.

\section{RESULTS}

Figure 1(A) shows a typical breakdown conditioning curve using molybdenum electrodes, where the maximum breakdown field is plotted as a function of the accumulated number of breakdown events. A detailed description of the realization and interpretation of such measurements can be found in [13]. In this particular case, a virgin ${ }^{1}$ cathode was employed, while the anode had undergone extensive breakdown conditioning prior to the run. From Fig. 1(A), one sees that the maximum obtained breakdown field increases rapidly during the first $\sim 50$ breakdowns, followed by a slow improvement until $\sim 200$ breakdowns. These values are found to be typical for the case of virgin cathode/

\footnotetext{
${ }^{1}$ Virgin surface stands in this article for a surface which has only been treated according to the CERN standards for UHV components.
} 
TABLE I. Saturated breakdown fields for $\mathrm{Cu}, \mathrm{Mo}$, and $\mathrm{W}$, and the effect of pressure of air, $\mathrm{CO}, \mathrm{H}_{2}$, and $\mathrm{Ar}$.

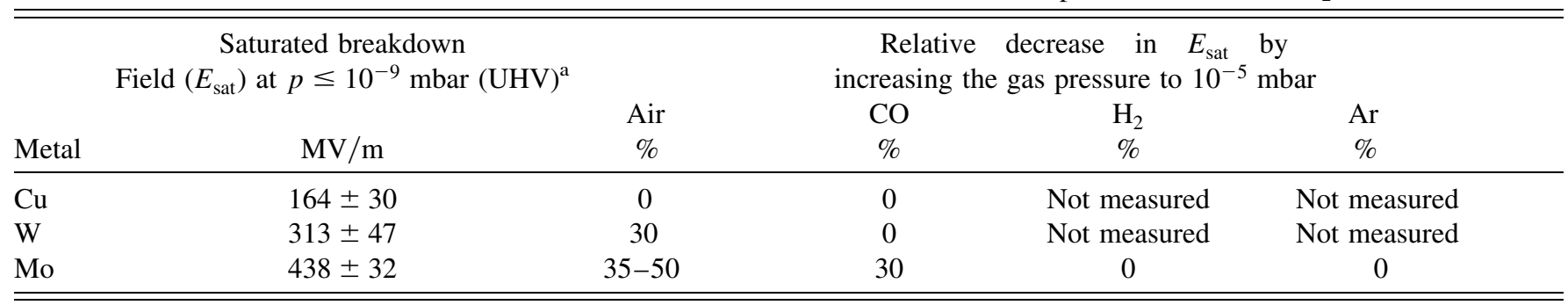

${ }^{\text {a }}$ The saturated breakdown fields at UHV conditions are the mean values and uncertainties of 3, 4 and 7 conditioning curves for $\mathrm{Cu}$, W and Mo, respectively. The higher $E_{\text {sat }}$ of Mo compared to W contradicts previously reported data. This difference is attributed to insufficient breakdown conditioning, that is, the saturation field of Mo was not reached in the experiment reported in $[7,13]$.

conditioned anode. In the case of virgin cathode/anode, measurements have been performed which point toward a slower conditioning speed, suggesting that also the anode has some influence on the overall breakdown evolution. When saturation is reached, air is introduced into the chamber at the pressures indicated in the upper part of Fig. 1(A). At $10^{-6}$ mbar, a gradual and significant decrease in $E_{\text {sat }}$ occurs, eventually reaching saturation approximately $150 \mathrm{MV} / \mathrm{m}$ below the level reached by ultrahigh vacuum (UHV) conditioning. When the low pressure is recovered (here $10^{-9}$ mbar range) $E_{\text {sat }}$ slowly recovers the initial value. Similar experiments have been performed on different molybdenum samples and with different gases. The results in Fig. 1(B) show the saturated breakdown fields as function of the gas type and pressure recorded inside the vacuum chamber. The lower horizontal axis shows the absolute pressure of $\mathrm{Ar}, \mathrm{CO}, \mathrm{H}_{2}$, and $\mathrm{O}_{2}$, while the upper shows the absolute pressure of air. The two horizontal axes are shifted relative to each other by a factor

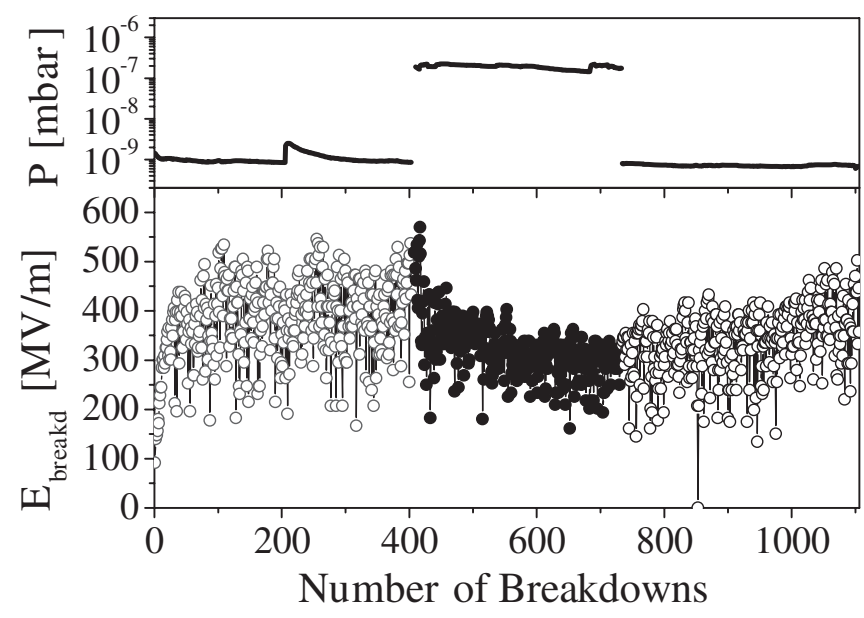

FIG. 2. Breakdown fields for molybdenum, and the effect of pure $\mathrm{O}_{2}$, as function of the accumulated number of breakdowns. The lower graph shows the breakdown conditioning curve for molybdenum, where the vertical axis denotes the maximum achieved applied electric field in $\mathrm{MV} / \mathrm{m}$ before breakdown. The upper graph shows the averaged pressure of $\mathrm{O}_{2}$ during each breakdown measurement. of 5 to match the amount of oxygen gas in dry air. Further measurements with elevated pressure of argon and $\mathrm{H}_{2}$ up to the $10^{-5}$ mbar range did not result in any detectable decrease in the breakdown field on molybdenum. For increasing pressures of $\mathrm{CO}$, a significant decrease of $E_{\mathrm{sat}}$ is observed, though somewhat weaker than for air exposure. Note that the shaded areas are guide to the eyes only to emphasize the different evolutions of the breakdown field between $\mathrm{CO}$ and air.

Identical measurements have been performed on the metals copper $(\mathrm{Cu})$ and tungsten $(\mathrm{W})$. The results are summarized in Table I, together with the results from the molybdenum measurements. As for Mo, also for $\mathrm{W}$ a significant decrease in the saturated breakdown field is recorded when the air pressure is increased from UHV to $1 \times 10^{-5}$ mbar, though the percentage decrease is on average smaller. Instead, for copper no such decrease is observed.

For exposure to $\mathrm{CO}$ only molybdenum exhibits a decrease in the maximum breakdown field, whereas no effect occurs for copper and tungsten. The relative decreases given in Table I are based on single gas exposure measurements; hence large uncertainties on the given values should be expected.

In order to understand which air component is relevant, a further experiment has been performed with pure $\mathrm{O}_{2}$ (Fig. 2). Apart from the expected factor of 5 in pressure, the effect on $E_{\text {sat }}$ is similar. Indeed, the relative decreases using $\mathrm{O}_{2}$ are measured to be $\sim 25 \%$ and $\sim 30-35 \%$ at $2 \times$ $10^{-7} \mathrm{mbar}$ and $2 \times 10^{-6} \mathrm{mbar} \mathrm{O}_{2}$, respectively. In comparison, $\sim 27 \%$ and $35 \%-50 \%$ are obtained for air pressures of $1 \times 10^{-6}$ mbar and $1 \times 10^{-5}$ mbar. $^{2}$ As for air, the highest $E_{\text {sat }}$ can be recovered when the $\mathrm{O}_{2}$ gas is pumped out and after sufficient reconditioning. These results strongly point towards oxygen as the main source for the observed decrease of $E_{\text {sat }}$ upon air exposure.

\footnotetext{
${ }^{2}$ For both the $\mathrm{O}_{2}$ and air measurements, each relative decrease is acquired during one breakdown conditioning, i.e., the samples, gap distances, and breakdown positions are kept unchanged.
} 


\section{A. Surface treatments}

To study in more detail the role surface oxidation has on the final $E_{\text {sat }}$, similar experiments were performed on molybdenum where the oxide layers were removed from the cathode surface by two distinctly different techniques: sputter cleaning with $\mathrm{Kr}^{+}$- or $\mathrm{Ar}^{+}$-ions and heat treatment. In both cases the cathode surface compositions were analyzed in parallel by XPS ex situ.

The sputter cleaning treatment was performed in a separate vacuum system. In the case of $\mathrm{Kr}^{+}$, the kinetic energy of the ions was about $0.3 \mathrm{keV}$, for a total dose of $2 \times$ $10^{18}$ ions $/ \mathrm{cm}^{2}$. The corresponding values for $\mathrm{Ar}^{+}$were $3 \mathrm{keV}$ and $2 \times 10^{16}$ ions $/ \mathrm{cm}^{2}$. In the latter case, the XPS measurement verified that no detectable amount of oxide was present before exposing the molybdenum surface to atmospheric air. Roughly $30 \mathrm{~min}$ were needed to perform the air transfer of the two sputter cleaned molybdenum foils to the system dedicated for breakdown experiments, and to pump the vacuum chamber to pressures $\leq$ $10^{-4}$ mbar. A bakeout of the UHV chamber to about $150{ }^{\circ} \mathrm{C}$ for $15 \mathrm{~h}$ was then performed. Figures $3(\mathrm{~A})$ and 3(B) show the resulting breakdown fields as a function of the accumulated number of breakdowns for surfaces sputter cleaned with $\mathrm{Kr}^{+}$and $\mathrm{Ar}^{+}$ions, respectively. The general behavior of the breakdown characteristics is seen to be similar and differs compared to the situation in Fig. 1(A). As for virgin molybdenum cathode surfaces, a close to linear increase in the breakdown field is observed up to $\sim 30-50$ events. However, the breakdown field ceases to increase beyond this stage, thus resulting in a significantly lower $E_{\text {sat }}$ than for nonsputtered surfaces. Intensive breakdown conditioning up two 650 events did not lead to any measurable increase.

After breakdown conditioning, the $\mathrm{Kr}^{+}$sputter cleaned molybdenum cathode was transferred to the XPS vacuum chamber for further analyses, leading to an additional half an hour of exposure to atmospheric air. The lower graph marked I in Fig. 4(A) shows the resulting XPS spectrum recorded from an area unaffected by breakdown conditioning. To ease the interpretation, a virgin molybdenum surface and an $\mathrm{Ar}^{+}$sputter cleaned surface (3 keV kinetic energy, total dose $2 \times 10^{16}$ ions $/ \mathrm{cm}^{2}$ ) were also investigated by XPS. The sputter cleaned sample shows Mo3 $d_{5 / 2}$ and $\mathrm{Mo} 3 d_{3 / 2}$ peaks at 227.6 and $230.7 \mathrm{eV}$, respectively, corresponding to molybdenum in the metallic state [1517] [Fig. 4(B), I]. The spectrum of the virgin surface, i.e., the initial situation for the native molybdenum material, shows the two dominant peaks at 235.5 and $232.4 \mathrm{eV}$ for the $\mathrm{Mo}_{3} d_{3 / 2}$ and $\mathrm{Mo} 3 d_{5 / 2}$ core levels, respectively [Fig. 4(B), III]. These energies are in the binding energy range of molybdenum species in their $\mathrm{VI}+$ oxidation states $[18,19]$. Other contributions found on the low binding energy side are significantly weaker, implying that the $\mathrm{Mo}^{\mathrm{VI}+}$ oxide layer is thick compared to the typical escape depth of the emitted core-electrons.

The two dominant peaks of molybdenum on the $\mathrm{Kr}^{+}$ sputter cleaned surface [Fig. 4(A), I] are broader and shifted with $\sim 0.5 \mathrm{eV}$ to higher binding energy compared with the measured metallic $\mathrm{Mo}^{0}$ peaks in Fig. 4(B), I. The small contribution observed at $\sim 234.6 \mathrm{eV}$ is attributed to the $\mathrm{Mo}^{\mathrm{IV}+} 3 d_{3 / 2}$ core level $[18,19]$. It has been demonstrated that these differences are caused primarily by air exposure and incomplete $\mathrm{Kr}^{+}$-sputtering.

The mid-XPS spectrum (II) in Fig. 4(A) shows the measurements performed inside the area modified by UHV breakdown conditioning. The binding energy positions and the width of the two dominant peaks are found to be identical to those of the freshly $\mathrm{Ar}^{+}$sputter cleaned surface [Fig. 4(B)], and are thus interpreted as originating from metallic molybdenum, $\mathrm{Mo}^{0}$. The lack of oxide shows
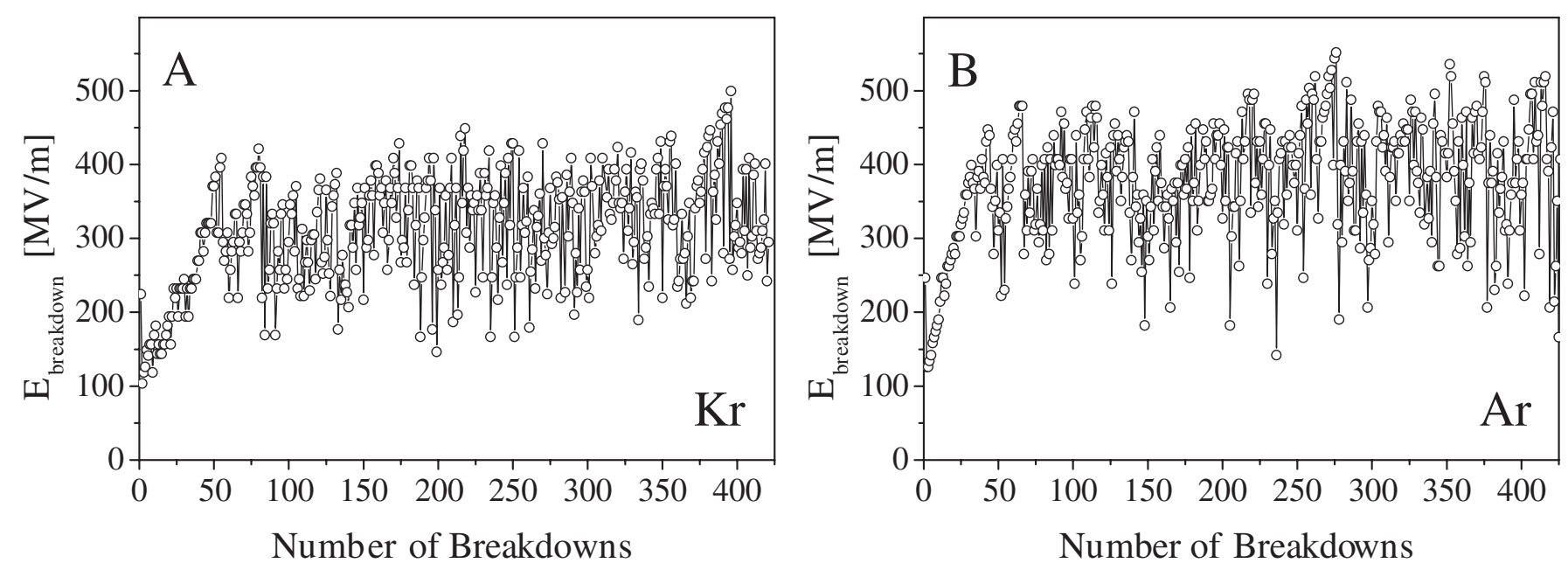

FIG. 3. Breakdown fields for molybdenum after ex situ sputter cleaning with (A) $0.3 \mathrm{keV} \mathrm{Kr}^{+}$ions and (B) $3 \mathrm{keV} \mathrm{Ar}^{+}$ions. The $E_{\text {sat }}$ are determined to be $(337 \pm 6) \mathrm{MV} / \mathrm{m}$ and $(395 \pm 5) \mathrm{MV} / \mathrm{m}$ for $\mathrm{Kr}^{+}$- and $\mathrm{Ar}^{+}$-ion treated molybdenum, respectively. During the conditioning the ambient pressure remained less than $10^{-9}$ mbar. 

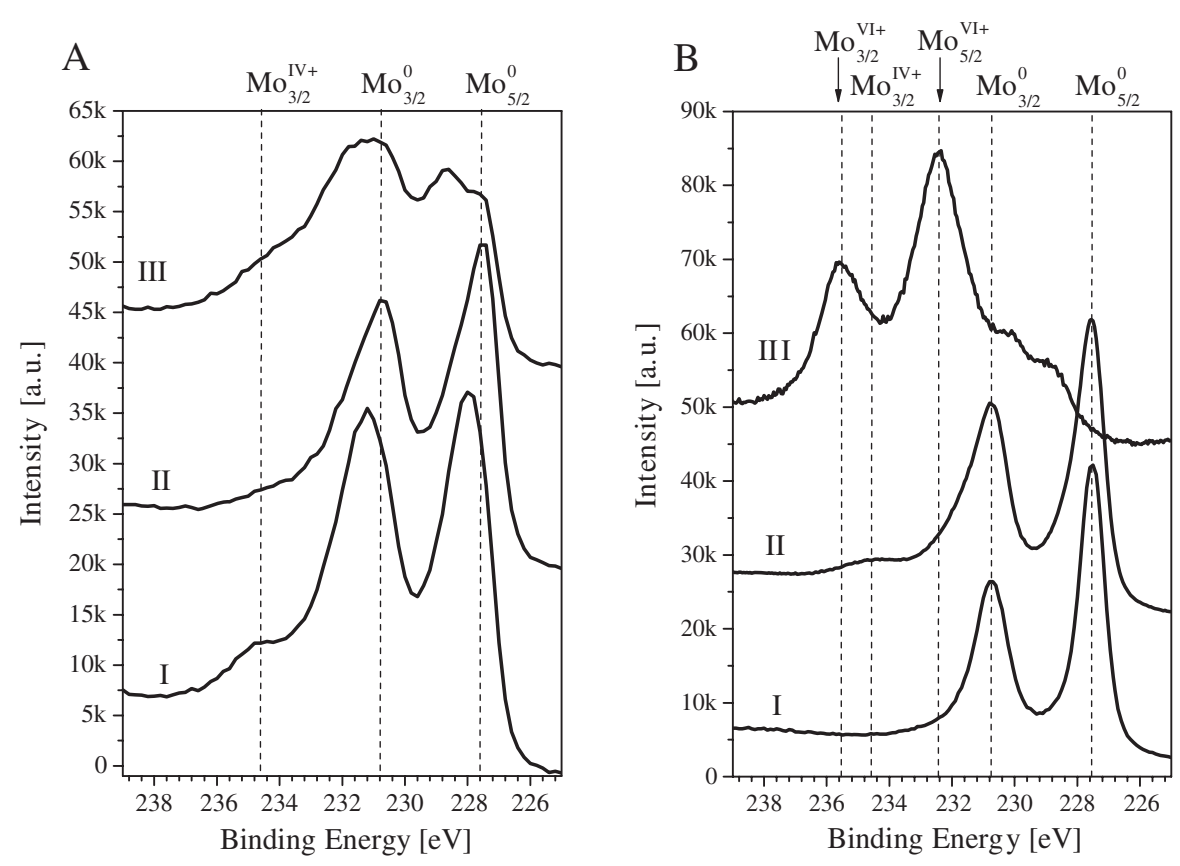

FIG. 4. Mo $3 d$ photoemission spectra. (A) Molybdenum surface after sputter cleaning with $\mathrm{Kr}^{+}$ion, plus $1 \mathrm{~h}$ exposure of atmospheric air. (I) Surface area unaffected by breakdown conditioning. (II) UHV breakdown conditioned area, (III) Area affected by breakdown conditioning during exposure of $\sim 2 \times 10^{-6} \mathrm{mbar}_{2}$. (B) Reference molybdenum sample. (I) $\mathrm{Ar}^{+}$sputter cleaned molybdenum surface. (II) Sample (I), followed by a $1 \mathrm{~h}$ exposure of atmospheric air. (III) Virgin molybdenum surface. All spectra are normalized to equal "peak-to-background" height relative to the most intense Mo $3 d^{5 / 2}$ peaks for clarity.

that the conditioning effectively removes oxide, an effect also reported in literature [10].

The upper XPS spectrum (III) in Fig. 4(A) shows the measurements inside the breakdown field area when breakdown conditioning was performed in oxygen pressures of up to $2 \times 10^{-6} \mathrm{mbar}$, i.e., where a significant decrease of $E_{\text {sat }}$ has been confirmed. This XPS spectrum appears to be more complex, where higher binding energy contributions from molybdenum oxide compounds coexist with metallic molybdenum. Because of insufficient energy resolution, a proper decomposition of the peaks is considered too ambiguous. However, by directly comparing this spectrum with the spectrum of the virgin molybdenum surface [Fig. 4(B), III], one can conclude that an intensive breakdown conditioning at oxygen ambience up to $2 \times$ $10^{-6}$ mbar does not produce significant amount of $\mathrm{Mo}^{\mathrm{VI}+}$ oxide species. This result is not surprising since it is known that molybdenum oxide in the form $\mathrm{MoO}_{3}$ has a high vapor pressure compared to other metal oxides $[20]^{3}$ and would thus be removed upon breakdown.

An alternative way of removing oxides is heat treatment in vacuum. Figure 5 shows the conditioning of a molybdenum cathode that has gone through heat treatments to temperatures $\geq \sim 1200 \mathrm{~K}$ and exposed to atmospheric air for more than $4 \mathrm{~h}$ prior to being installed in the spark

\footnotetext{
${ }^{3}$ That is, at $923 \mathrm{~K}$ the vapor pressure of $\mathrm{MoO}_{3}$ is found to be 0.1 mbar.
}

system. Visual inspection of the surface after the heat treatment showed no signs of recrystallization. The result is a close to immediate increase to $E_{\text {sat }}$ of $(459 \pm$ 2) $\mathrm{MV} / \mathrm{m}$, a value typically seen only after intensive breakdown conditioning of virgin molybdenum cathodes [Fig. 1(A)]. Prior to being transferred to the spark system, XPS measurements showed virtually no traces of surface

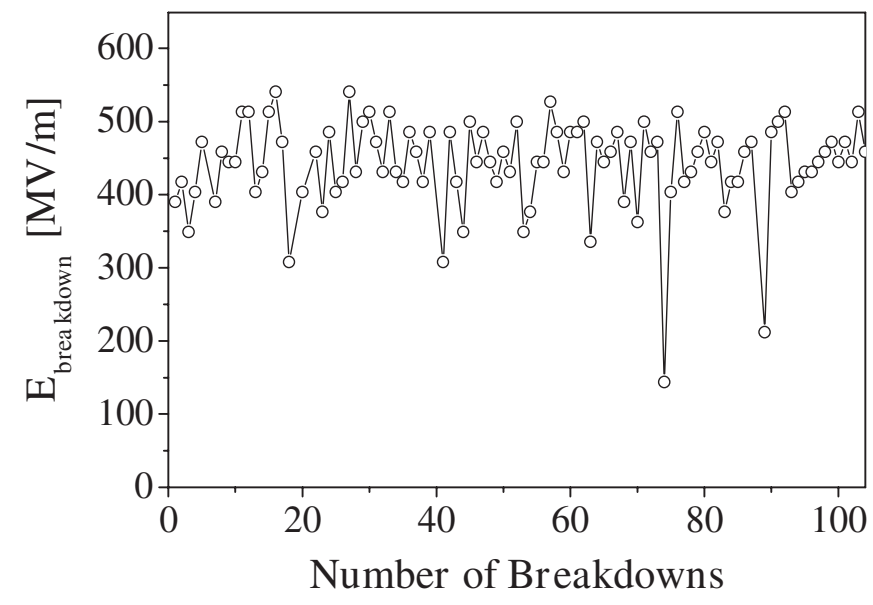

FIG. 5. Breakdown conditioning after $e x$ situ heat treatments of molybdenum to temperatures $\geq \sim 1200 \mathrm{~K}$ in vacuum $(p<$ $10^{-4}$ mbar), followed by more than $4 \mathrm{~h}$ in atmospheric air. The $E_{\text {sat }}$ are determined to be $(459 \pm 2) \mathrm{MV} / \mathrm{m}$. 
oxides. The initial oxidation states of the molybdenum cathodes in Figs. 5 and 3(B) are thus similar at the start of the conditioning. Furthermore, when $E_{\mathrm{sat}}$ is reached, the measured enhancement factor for the electric field $(\beta)$, a value closely linked to the topography of the surface [1], is found to be in average comparable in the three reported cases, i.e., virgin, heat treated and sputter cleaned molybdenum. Hence, the origin of the low $E_{\text {sat }}$ observed in Fig. 3 is at present not clear. One could speculate that implantations of $\mathrm{Kr}^{+}$and $\mathrm{Ar}^{+}$ions during the high energy bombardment influence $E_{\text {sat }}$.

The positive effect of vacuum heat treatment on the breakdown characteristics has been reported previously on copper [21-24] and stainless steel [25]. Heat treatments of copper and stainless steel have been shown to reduce the density of field emission sites, resulting in a more rapid initial conditioning $[25,26]$. Similar studies on molybdenum are to the best of our knowledge not performed. It is however likely that the initial conditioning seen in Figs. 13 results from removal of both field emitters and foreign species. It must be emphasized that the reported improvements in the breakdown characteristics were obtained after heat treatments in vacuum. In contrast, recent experiments performed on a copper National Linear Collider prototype $\mathrm{X}$-band structure [27] showed a higher breakdown rate when the structure was vented to filtered air during a heating to about $160{ }^{\circ} \mathrm{C}$.

\section{DISCUSSION}

It is well known that adsorbed gas layers [28] and dielectric surface layers $[1,10]$ can lead to additional electron emission mechanisms through Joule heating and ion activations, and thereby influence the breakdown level [29,30]. In Fig. 1 it is demonstrated that during intensive breakdown conditioning of Mo and $\mathrm{W}$ in gas ambience up to $10^{-5}$ mbar, only oxygen and $\mathrm{CO}$ among the probed gases have a measurable negative effect on $E_{\text {sat }}$. For $\mathrm{Cu}$ no such influence on $E_{\text {sat }}$ is observed. To better understand the cause of these observations, a detailed literature study of the interaction between the reported gases and electrode materials has been carried out.

\section{A. Air/Oxygen}

Because of its importance in catalytic industries, oxidation of molybdenum is well documented in literature [31]. For polycrystalline molybdenum no oxidation takes place at room temperature for $\mathrm{O}_{2}$ exposure of up to $\sim 10^{3} \mathrm{~L}$ [19]. Oxygen exposure of $1 \mathrm{~atm}$ for $1 \mathrm{~h}$ at a temperature of $200^{\circ} \mathrm{C}$ is reported to give a partial oxidation on polycrystalline molybdenum, with an apparent coexistence of $\mathrm{Mo}^{0}$, $\mathrm{Mo}^{\mathrm{IV}+}, \mathrm{Mo}^{\mathrm{V}+}$, and $\mathrm{Mo}^{\mathrm{VI}+}$ species. Annealing to $400^{\circ} \mathrm{C}$ removes traces of pure molybdenum and the remaining species are identified as $\mathrm{Mo}^{\mathrm{VI}+}$, presumably in the form of amorphous $\mathrm{MoO}_{3}$ [18]. Oxidation can also be formed on polycrystalline molybdenum by reactive oxygen plasma or $\mathrm{O}_{2}{ }^{+}$bombardment, where the former technique produces a mixture of $\mathrm{Mo}^{\mathrm{IV}+}, \mathrm{Mo}^{\mathrm{VI}+}$, and $\mathrm{Mo}^{n+}(n<4)$ species, and the latter mainly $\mathrm{Mo}^{n+}(n<4)$ [19]. In the case of breakdown conditioning in oxygen gas, oxygen will be incorporated into the plasma formation leading to the breakdown, and thereby create conditions similar to the situation investigated by López-Carreño et al. [19]. In addition, the breakdown itself heats the cathode significantly, creating favorable conditions for oxidation in presence of $\mathrm{O}_{2}$. The two effects give a plausible explanation for the obtained XPS results reported in Fig. 4(A). If oxide is recognized as the cause of the observed degradation, the close to exponential decay of the $E_{\text {sat }}$ [Figs. 1(A)-3] would be the consequence of a balance between the oxide formation and the oxide removal rate due to the successive electrical breakdown events.

On polycrystalline tungsten, $\mathrm{O}_{2}$ molecules are found to dissociate at room temperature and to form oxides of stoichiometry $\mathrm{WO}_{3}, \mathrm{WO}_{3-x}(0<x<1)$, and $\mathrm{WO}_{2}$ at increasing temperatures [32-35]. Although XPS measurements and oxygen breakdown experiments as described above have not yet been performed on tungsten, it is speculated that the observed decrease in $E_{\text {sat }}$ in air ambience (Table I) is closely linked to the formation of oxides in the same way as for polycrystalline molybdenum.

Also copper oxides are easily formed when a metallic copper surface is heated in an air/oxygen ambience. As for tungsten, their stoichiometry is strongly temperature dependent, following the sequence $\mathrm{Cu}_{x} \mathrm{O}, \mathrm{Cu}_{2} \mathrm{O}, \mathrm{Cu}_{3} \mathrm{O}_{2}$, and $\mathrm{CuO}$, for annealing temperatures of $<343,343-383,383-$ 473, and 543-603 K, respectively [36,37]. Breakdown conditioning in air ambience is hence expected to cause a significant oxidation on the copper surface. However, contrary to what is observed during breakdown conditionings of molybdenum and tungsten electrodes, the copper oxide(s) do not cause any measurable degradation of $E_{\text {sat }}$ (Table I).

A possible explanation for this apparent contradiction can be that the formed copper oxides are easily removed from the surface due to vaporization and/or oxygen diffusion into the bulk prior to breakdown. In Table II the "heat of formation" ${ }^{4}$ is given for the integral order oxides [38]. With the exception of $\mathrm{MoO}_{3}$, i.e., the oxide found to be insignificant during breakdown conditioning [Fig. 4(A), $\mathrm{II}]$, the heat of formation is significantly higher for Mo and $\mathrm{W}$ oxides than $\mathrm{Cu}_{2} \mathrm{O}$ and $\mathrm{CuO}$. In addition, the diffusion of oxygen into the bulk of copper proceeds faster than for tungsten and molybdenum at $1000 \mathrm{~K}$, as seen from the reported values in Table II [39]. ${ }^{5}$

\footnotetext{
${ }^{4}$ The heat of formation refers to the heat necessary for the formation of $1 \mathrm{~mol}$ of oxygen in solid phase.

${ }^{5}$ The tabulated diffusion values are found by averaging over all the measured values reported in Ref. [39].
} 
TABLE II. (Top) Heat of formation of some oxide compounds of $\mathrm{Mo}, \mathrm{W}$, and $\mathrm{Cu}$. (Bottom) Average values for diffusion coefficient $\left(D^{0}{ }_{\text {av }}\right)$, activation energy $\left(Q_{\mathrm{av}}\right)$ and diffusion at $1000 \mathrm{~K}$ for oxygen atoms through bulk molybdenum, tungsten, and copper.

\begin{tabular}{|c|c|c|c|}
\hline Compound & & \multicolumn{2}{|c|}{ Heat of formation $\left[\mathrm{kJ} / \mathrm{mol} \mathrm{O}_{2}\right]$} \\
\hline $\mathrm{MoO}$ & & \multicolumn{2}{|c|}{$\cdots$} \\
\hline $\mathrm{MoO}_{2}$ & & \multicolumn{2}{|c|}{588.7} \\
\hline $\mathrm{MoO}_{3}$ & & \multicolumn{2}{|c|}{324.9} \\
\hline $\mathrm{WO}_{2}$ & & \multicolumn{2}{|c|}{589.9} \\
\hline $\mathrm{WO}_{3}$ & & \multicolumn{2}{|c|}{561.5} \\
\hline $\mathrm{CuO}$ & & \multicolumn{2}{|c|}{286.4} \\
\hline $\mathrm{Cu}_{2} \mathrm{O}$ & & \multicolumn{2}{|c|}{334.9} \\
\hline & $\begin{array}{c}D^{0}{ }_{\mathrm{av}} \\
{\left[\mathrm{m}^{2} \mathrm{~s}^{-1}\right]}\end{array}$ & $\underset{[\mathrm{kJ} / \mathrm{mol}]}{Q_{\mathrm{av}}}$ & $\begin{array}{c}D_{\mathrm{av}} \text { at } 1000 \mathrm{~K} \\
{\left[\mathrm{~m}^{2} \mathrm{~s}^{-1}\right]}\end{array}$ \\
\hline $\mathrm{O}$ in $\mathrm{Mo}$ & $2.9 \times 10^{-2}$ & 117.6 & $2.1 \times 10^{-8}$ \\
\hline $\mathrm{O}$ in $\mathrm{W}$ & $1.3 \times 10^{-4}$ & 100.5 & $7.3 \times 10^{-10}$ \\
\hline $\mathrm{O}$ in $\mathrm{Cu}$ & $2.6 \times 10^{-2}$ & 69.4 & $6.2 \times 10^{-6}$ \\
\hline
\end{tabular}

Both phenomena thus support the assumption that differences in $E_{\text {sat }}$ degradation between the elements can be attributed to different balance between oxide formation and removal during breakdown.

Several models have been proposed that describe the influence of dielectrics on metal surfaces $[1,10]$. Founded on breakdown measurements of $\mathrm{SiO}_{2}$ thin films, Ridley [29] and DiStefano et al. [30] proposed two different models for breakdown initiation in dielectrics, both based on formation of positive ions from field emission current and enhanced Joule heating. The former model of Ridley et al. addresses the effects of the mobile ions produced through dissociation of neutral impurity species due to Joule heating. The activated positive ions lead to an avalanche process of enhanced field emission, steeper temperature rise, and eventually cause a thermal runaway towards breakdown. In contrast, in the model of DiStefano et al., slow-moving holes are produced through ionization of the lattice by hot field emitted electrons. When the ions are formed, the positive cloud initiates processes similar to those described by Ridley et al., i.e., enhanced field emission current, temperature rise through Joule heating, thermal runaway, and eventually breakdown. The $\mathrm{MoO}_{3}$ film present on a virgin Mo surface [Fig. 4(B), III] may fulfill the requirements for Ridley's model since the oxide formation took place in nonclean conditions. However, it is likely that the molybdenum oxide developed during the controlled inlet of air and oxygen (Figs. 1 and 2) with base pressures $<10^{-9} \mathrm{mbar}$ is too pure to create the necessary density of impurities. Thus, in this case the model of DiStefano et al. could be more adapted. However, the idea that positive ions produced by field emission electrons enable high enough Joule heating to cause thermal runaways, is common for both models. Thermal runaways can also be simulated using a model proposed by Williams et al. [40]. By calculating the amount of Joule heating in a cylindrical protrusion, a threshold current can be found where runaway effects start. Because of the poorer electric and thermal conductivities of oxide films, this threshold is shown to be lowered compared with pure metals.

\section{B. $\mathrm{H}_{2}, \mathrm{Ar}, \mathrm{CO}, \mathrm{H}_{2} \mathrm{O}$}

From the measurements presented in Figs. 1-4, it is clear that exposure to oxygen gas has a negative effect on $E_{\text {sat }}$ in the case of polycrystalline molybdenum. However, in a real rf system oxygen partial pressures sufficient to cause any significant effect of $E_{\text {sat }}$ are not likely since $\mathrm{O}_{2}$ is effectively adsorbed on the stainless steel chamber walls with very low desorption rates [41]. Hence, for properly baked vacuum systems, mostly $\mathrm{H}_{2}, \mathrm{~N}_{2}$, Ar, $\mathrm{CO}, \mathrm{CO}_{2}, \mathrm{CH}_{4}$, and traces of $\mathrm{H}_{2} \mathrm{O}$ vapor are present [42]. From Fig. 1(B) it is clear those exposures of $\mathrm{H}_{2}$, $\mathrm{N}_{2}$, and Ar have no measurable influence on $E_{\text {sat }}$ within the studied pressure range. Furthermore, due to the similar decrease during exposure of dry and laboratory air up to $10^{-6}$ mbar, it is concluded that $\mathrm{H}_{2} \mathrm{O}$ vapor does not have any major effect on $E_{\text {sat }}$ for partial pressure less than $\sim 2 \times 10^{-8}$ mbar. $^{6}$

$\mathrm{CO}$ dissociation is reported to occur at room temperature, both on polycrystalline molybdenum $[43,44]$ and tungsten [45-47], thus causing an accumulation of oxygen atoms on the surface. By following the same reasoning as for breakdown conditioning in air/oxygen ambience, a decrease of $E_{\text {sat }}$ at high CO pressure is anticipated for both materials. Such degradation is measured for molybdenum (Table I), but not for tungsten. Why this is the case is at present not clear. It is reasonable to assume that the adsorption of carbon on the surface and the formation of carbides will have an affect $E_{\text {sat }}$. On molybdenum, $\mathrm{Mo}_{2} \mathrm{C}$ starts to form already at room temperature [48], while formation of carbides of stoichiometry $\mathrm{W}_{2} \mathrm{C}$ and $\mathrm{WC}$ are initiated at elevated temperatures [49]. In both cases, carburization reduces the dissociation rates of $\mathrm{CO}$ molecules significantly [50,51], thereby impeding further oxidation.

As mentioned in the Introduction, the pressure in the CTF3 accelerator structure increases significantly at the moment of breakdown. Mass spectroscopy measurements show that the gas released from the molybdenum electrodes at the moment of dc breakdown consist mainly of $\mathrm{H}_{2}$ and $\mathrm{CO}$ [52]. The observed degradation of $E_{\text {sat }}$ during dc breakdown conditioning in $\mathrm{CO}$ ambience could for this reason be an important limitation for the future CLIC.

\footnotetext{
${ }^{6}$ It is here assumed that the water content in the laboratory air is roughly $2 \%$.
} 


\section{SUMMARY}

In this paper a comprehensive investigation is presented to determine what influence various ambient gases in the pressure range $\leq 10^{-5}$ mbar have on the breakdown holdoff capability of molybdenum, tungsten, and copper during intensive breakdown conditioning. For the refractory metals tungsten and molybdenum, a significant decrease of the saturated breakdown field is observed at elevated air pressures. For molybdenum this effect is also observed during similar $\mathrm{CO}$ exposures. The gases $\mathrm{Ar}$ and $\mathrm{H}_{2}$ show no measurable influence on the breakdown field of molybdenum. Results from careful breakdown measurements in oxygen ambience and x-ray photoemission spectroscopy measurements strongly point towards oxide formation as the source for the observed decrease. Removal of molybdenum oxide films by ex situ heat treatment is shown to improve the breakdown characteristics drastically.

\section{ACKNOWLEDGMENTS}

H. Neupert provided expert technical advice and assistance before and during the experiments. W. Wuensch is acknowledged for extended fruitful and interesting discussions about rf and dc breakdown phenomena. A. Chamot is honorably mentioned for his excellent and enthusiastic participation during the experiments.

[1] See, e.g., High Voltage Vacuum Insulation, edited by R. V. Latham (Academic, New York, 1995).

[2] D. Lopez, F. Pardo, C. Bolle, R. S. Decca, and D. J. Bishop, Low Temp. Phys. 135, 51 (2004).

[3] S. Itoh, M. Tanaka, and T. Tonegawa, J. Vac. Sci. Technol. B 22, 1362 (2004).

[4] See, e.g., Principles of RF Linear Accelerators, edited by T. P. Wangler (John Wiley \& Sons, Inc., New York, 1998).

[5] CERN-2000-008, CERN, Geneva, 2000; J.P. Delahaye et al., Proceedings of the 1999 Particle Accelerator Conference (IEEE, New York, 1999), Vol. 1, p. 250.

[6] C. Achard, H. Braun, S. Döbert, I. Syratchev, M. Taborelli, I. Wilson, and W. Wuensch, CLIC Note 569, CERN, Geneva, Switzerland, 2003; Particle Accelerator Conference PAC 2003 (IEEE, Portland, Oregon, 2003), p. 495.

[7] M. Taborelli, M. Kildemo, and S. Calatroni, Phys. Rev. ST Accel. Beams 7, 092003 (2004).

[8] R. Corsini, G. Geschonke, L. Rinolfi, and F. Tecker, CLIC Note 622, CARE Note-2004-025-ELAN.

[9] W. Wuensch (private communication).

[10] S. Anders and B. Jüttner, IEEE Trans. Plasma Phys. 19, 705 (1991), and references therein.

[11] B. Jüttner, H. Wolff, and B. Altrichter, Phys. Status Solidi (a) 27, 403 (1975).

[12] B. Jüttner, H. Pursch, and P. Siemroth, Wissensch. Mitteil. D. Instr. 19, 5 (1978).

[13] M. Kildemo, Nucl. Instrum. Methods Phys. Res., Sect. A 530, 596 (2004).
[14] C. Scheuerlein and M. Taborelli, Appl. Surf. Sci. 252, 4279 (2005).

[15] Handbook of X-ray Photoelectron Spectroscopy (PerkinElmer Corp., Physical Electronics Division, Eden Prairie, MN, 1978), p. 104.

[16] P. A. Spevack and N. S. McIntyre, J. Phys. Chem. 97, 11020 (1993).

[17] J. A. Rodriguez and M. Kuhn, J. Vac. Sci. Technol. A 14, 1609 (1996).

[18] A. Galtayries, S. Wisniewski, and J. Grimblot, J. Electron Spectrosc. Relat. Phenom. 87, 31 (1997).

[19] L. D. López-Carreño, G. Benítez, L. Viscido, J. M. Heras, F. Yubero, J. P. Espinós, and A. R. Gonzáles-Elipe, Surf. Interface Anal. 26, 235 (1998).

[20] Y. Li, K. Galatsis, W. Wlodarski, M. Ghantasala, S. Russo, J. Gorman, S. Santucci, and M. Passacantando, J. Vac. Sci. Technol. A 19, 904 (2001).

[21] A. Watson, Proceedings of the X International Symposium on Discharge and Electrical Insulation in Vacuum (1982), p. 83.

[22] S. Kobayashi, Y. Hashimoto, M. Maeyama, Y. Saito, and Y. Nagai, Vacuum 47, 745 (1996).

[23] S. Kobayashi, IEEE Trans. Dielectr. Electr. Insul. 4, 841 (1997).

[24] T. Yamamoto, T. Otsuka, Y. Yamano, S. Kobayashi, T. Higo, N. Toge, K. Takata, Y. Higashi, Y. Saito, and N. Hitomi, Trans. Inst. Electr. Eng. Jpn. A 123-A, 468 (2003).

[25] D. I. Proskurovsky, A. V. Batrakov, V. P. Rotshtein, K. V. Karlik, and D. J. Johnson, Proceedings of the 14th IEEE International Pulsed Power Conference, 2003, Vol. 1, p. 297.

[26] E. Takahashi and M. Sone, IEEE Trans. Dielectr. Electr. Insul. 5, 929 (1998).

[27] L. Laurent, C. Adolphsen, S. Beebe, S. Döbert, N.C. Luhmann, Jr., C. Pearson, J.A. Rodriguez, G. Scheitrum, and W. Wuensch, SLAC-PUB-12050, Stanford, 2006.

[28] B. M. Smirnov, Negative Ions (Atomizdat, Moscow, 1978), p. 176; translation in English available at McGraw-Hill, New York, 1982.

[29] B. K. Ridley, J. Appl. Phys. 46, 998 (1975).

[30] T. H. DiStefano and M. Shatzkes, J. Vac. Sci. Technol. 13, 50 (1976).

[31] S. I. Castañeda, I. Montero, J. M. Ripalda, N. Dìas, L. Galán, and F. Rueda, J. Appl. Phys. 85, 8415 (1999), and references therein.

[32] A. K. Mazumdar and H.-W. Wassmuth, Surf. Sci. 30, 617 (1972).

[33] D. Auerbach, C. Becker, J. Cowin, and L. Wharton, Applied Physics 14, 141 (1977).

[34] J. Lepage, A. Mezin, and M. Nivoit, Surf. Sci. 161, 255 (1985).

[35] Tungsten, Properties, Chemistry, Technology of the Element, Alloys, and Chemical Compounds, edited by E. Lassner and W.-D. Schubert (Kluwer Academic/Plenum Publishers, New York, 1999), 1st ed.

[36] H. Wieder and A. W. Czanderna, J. Phys. Chem. 66, 816 (1962).

[37] D. L. Cocke, R. Schennach, M. A. Hossain, D. E. Mencer, H. McWinney, J. R. Parga, M. Kesmez, J. A. G. Gomes, and M. Y. A. Mollah, Vacuum 79, 71 (2005). 
[38] The Oxide Handbook, 2nd ed., edited by G. V. Samsonov (Kluwer Academic, New York, 1982).

[39] A. D. LeClaire, in Diffusion in Solid Metals and Alloys, Landolt-Börnstein, New Series Group III, Vol. 26 (Springer-Verlag, Heidelberg, 1990), p. 478, and references therein.

[40] D. W. Williams and W. T. Williams, J. Phys. D 5, 280 (1972).

[41] CERN 99-05, Geneva, 1999.

[42] C. P. Gopalaraman and R. D. Luktuke, Vac. News 4, 3 (1973).

[43] S. J. Atkinson, C. R. Brundle, and M. W. Roberts, Chem. Phys. Lett. 24, 175 (1974).

[44] S. J. Atkinson, S.R. Brundle, and M. W. Roberts, J. Electron Spectrosc. Relat. Phenom. 2, 105 (1973).
[45] G. Brodén, T. N. Rhodin, C. Brucker, R. Benkow, and Z. Hurych, Surf. Sci. 59, 593 (1976).

[46] C. G. Goymour and D. A. King, J. Chem. Soc., Faraday Trans. 1 69, 736 (1973).

[47] J. T. Yates, T. E. Madey, and N. E. Erickson, Surf. Sci. 43, 257 (1974).

[48] P. Reinke and P. Oelhafen, Surf. Sci. 468, 203 (2000).

[49] J. Luthin and C. Linsmeier, Surf. Sci. 454-456, 78 (2000).

[50] J. Hrbek and J. Pavlíček, Chem. Phys. Lett. 80, 139 (1981).

[51] J. Wang, M. Castonguay, J. Deng, and P. H. McBreen, Surf. Sci. 374, 197 (1997).

[52] T. Ramsvik, P. Pinto, S. Calatroni, and M. Taborelli (to be published). 